\title{
LA DOCTRINA DE LA REVISIÓN JUDICIAL Y LA OBLIGACIÓN DE OBEDECER EL DERECHO
}

\author{
Idowu W. William \\ Obafemi Awolowo University \\ ILE-IFE, Nigeria
}

RESUMEN. El autor estudia la conexión entre la revisión judicial de las leyes y el problema de la obediencia al Derecho. En particular, intenta mostrar de qué manera un análisis acerca de la doctrina de la revisión judicial, contribuye a resolver algunas cuestiones relacionadas con el problema de la obediencia al Derecho. En su opinión "la obligación de obedecer el Derecho deriva de la conformidad de una regla jurídica con una norma externa [...] el contenido moral de la ley define o determina si se genera una obligación de obedecer el Derecho". Partiendo del análisis de la revisión judicial a la luz de la idea de obligación jurídica, el autor concluye que "no hay obligación prima facie de obedecer una ley perniciosa o injusta cuando existen limitaciones a la autorización para crear leyes”. La obligación de obedecer el Derecho es moral, lo que quiere decir que "deriva del contenido del Derecho y, por tanto, que es externa al mismo".
ABstract. The author studies the connection between the judicial review of laws and the problem of obedience to the law. In particular, the author tries to show the way in which an analysis of the judicial review doctrine contributes to the solving of a number of questions related to the problem of obedience to the law. In the author's opinion, "the obligation to obey the law derives from the accordance existing between a legal norm and an external norm [...] the moral content of the law defines or determines whether an obligation to obey the law is created". Taking as a starting point the analysis of the judicial review, considered in the light of legal obligation, the author concludes that "there is no prima facie obligation to obey a pernicious or unjust law when limitations exist on the authorization to create laws". The obligation to obey the law is a moral one, which means that "it derives from the content of law and, therefore, it is external to it”. 


\section{Introducción}

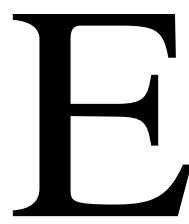

l Derecho constituye una de las más grandes instituciones y prácticas sociales jamás desarrolladas por el hombre. Éste representa un gran paso en la evolución cultural y si alguna vez la civilización perece se deberá, en parte, a nuestro fallo por comprender el potencial del "rule of law". En tiempos recientes ha surgido una creencia generalizada según la cual, el hecho de que un Abacha, o un Kabila, o un Mugabe, dicten una ley mediante una siniestra influencia sobre el poder legislativo, constituye una condición necesaria y suficiente para que dicha ley sea obedecida. Frecuentemente, estos puntos de vista descuidan el contenido de las leyes en cuestión. Este trabajo pretende mostrar que tal actitud responde a un error y que es por tanto falsa.

De acuerdo con Judith Sklar, algunas disputas filosóficas rara vez se resuelven, en tanto que otras, tienden a desaparecer. Sin embargo, hay algunas controversias que poseen una extraordinaria aptitud de supervivencia ${ }^{2}$. La teoría de la obligación se sitúa en dicho ámbito: constituye uno de esos temas controversiales relacionados con la naturaleza del Derecho y que son de gran preocupación para los filósofos del Derecho. Este trabajo estudia la naturaleza del problema de la obligación de obedecer el Derecho, y muestra que el análisis de la doctrina de la revisión judicial puede contribuir a resolver algunas cuestiones relacionadas con el problema que nos ocupa.

\section{El concepto y el problema de la obligación de obedecer el Derecho}

A lo largo de la historia de las ideas políticas y jurídicas, filósofos políticos y del Derecho han estado divididos en torno a un concepto fundamental: el de la obligación ${ }^{3}$. Por ejemplo, uno puede preguntarse ¿qué

\footnotetext{
${ }^{1}$ J.C. Smith, Legal Obligation (London: Athlone Press, 1976) Ver prefacio.

2 Judith Sklar, Legalism (Massachussets, 1964) p. 29.

${ }^{3}$ Prueba de ello es la abundante bibliografía acerca del concepto de obligación que se halla en la filosofía del Derecho, moral y política. Ver, por ejemplo, A. John Simmons, Moral Principles and Political Obligation (Princeton, Princeton University Press, 1979); Rolf Sartorius, "Polítical Authority and Political Obligation”, Virginia Law Review, vol. 67, (1981); Harry Beran, The Consent Theory of Obligation (London, Croom Helm, 1987); Michael Walzer, "The Obligation to Disobey”, in Edward Kent, (ed.), Revolution and the Rule of Law (Englewood cliffs, N.J, Prentice-Hall, Inc., 1971); Tony Honore, "Must we Obey?, Necessity as Ground of Obligation”, Virginia Law Review vol, 67, Feb (1981); J.C. Smith, Legal Obligation, (London, Athlone Press, University of London, 1976); R.J. Bernstein, "Prof Hart on Rules of Obligations”, Mind vol. 73 (1964); Henry Hart, “The aims of the Criminal Law”, Law and Contemporary Problems vol. 23, (1958); A.C. Woozley, Law and obedience (1979); Hart, H.L.A., "Legal and Moral Obligations” en A.I. Melden (ed.), Essays in Moral Philosophy (Seattle: University of Washington Press, 1958); Josep Raz, The Authority of Law (Oxford: Oxford University Press, 1979), etc.
} 
son las obligaciones? ¿ंTenemos y necesitamos obligaciones? En particular, mi propósito es profundizar en la conexión que puede encontrarse entre la doctrina y la práctica de la revisión judicial y el problema de la obediencia al Derecho. Para llevarlo a cabo intentaré responder a dos preguntas relacionadas con el propósito de este trabajo: ¿Existe siempre una obligación de obedecer el Derecho con independencia de "cualquier otro tipo de consideraciones” en la medida en que la regla en cuestión es una ley? ¿Puede siempre sostenerse que una "ley prohibida" y una "ley permitida" ${ }^{4}$ generan por igual una obligación?

\section{La naturaleza de la obligación y de los deberes}

Una comprensión cabal acerca de la idea de obediencia al Derecho presupone, en mi opinión, una reflexión previa acerca de la idea de la obligación en sí misma. En este sentido, uno puede preguntarse ¿qué son las obligaciones? El concepto de obligación es frecuentemente utilizado como sinónimo del concepto de deber; ambos conceptos, como se verá más adelante, poseen la misma estructura que los enunciados de deber. Estos enunciados expresan un imperativo e implican un estándar para una evaluación específica. Algunas conductas son ponderadas, evaluadas y juzgadas de acuerdo con estándares específicos o establecidos, y, sobre esa base, son evaluadas como correctas o incorrectas. Un enunciado que enfatice o que incorpore dichos juicios o evaluaciones acerca de lo que alguien "deba hacer", de que alguien tenga la obligación o el deber de hacer algo, o lo contrario, es, en gran medida, una declaración acerca de que hay buenas razones para realizar el acto, o de que habrá consecuencias en caso contrario. Es por eso que en la mayoría de los enunciados de "deber" u "obligación" -que incorporan dichos juicios y evaluaciones-, generalmente, pero no en todos los casos, se acompaña la expresión "por qué"

Para A. John Simmons, las obligaciones son requerimientos morales generados mediante la realización de un acto voluntario $0^{6}$. Siguiendo al mismo autor, los deberes son "deberes relativos al cargo" o bien deberes morales?. Los primeros hacen referencia a aquellos deberes que se poseen en virtud

\footnotetext{
${ }^{4}$ Las frases entrecomilladas son tomadas del voto particular del juez John Marshall en el caso Marbury v. Madison (1803). Estas expresiones, a mi parecer, están llenas de controversias. En mi opinión, tales controversias puede ser discutidas con el fin de establecer su alcance. De la misma manera, responden a la pregunta acerca de si un acto declarado inválido sigue siendo una ley o no.

${ }^{5}$ J. C. Smith, Legal Obligation (London: Athlone Press, University Press, 1979), p. 35.

${ }^{6}$ A. John Simmons, Moral Principles and Political Obligation (Princeton: Princeton University Press, 1979), p. 11.

${ }^{7}$ Ibíd. p. 12.
} 
de un puesto público; mientras que los deberes morales son aquellos que se poseen en virtud de la pertenencia a la raza humana. Por tanto, los primeros hacen referencia a un cargo público como el del juez, el del policía y otros similares, con facultades expresas o deberes específicos que se deben desempeñar. Los últimos hacen referencia a nuestro deber natural como seres humanos para ayudar a todo aquel que lo necesite. Y así, según Simmons, los deberes relativos al cargo son moralmente vinculantes únicamente cuando un cargo público es asumido voluntariamente.

A la luz del anterior análisis, un examen acerca de la naturaleza de los deberes, y de las variadas distinciones que pueden hacerse acerca del concepto de deber, puede ayudar a una adecuada comprensión acerca del concepto de obligación. Lo anterior se debe a que los deberes son una especie del género obligación, en tanto que se pueda afirmar que ambos son conceptos normativos, -i.e., que expresan prescripciones y evaluaciones-, a pesar de que no en todos los sentidos una obligación tenga el mismo significado que el de un deber. En este sentido, se puede distinguir entre deberes prima facie y deberes concluyentes. Los deberes prima facie son deberes que conllevan una presunción a favor de su obediencia. Argumentar en contra de las presunciones que subyacen a estos deberes implica dar razones que muestren que alguien no tiene tales deberes. En caso de que aquellas razones no sean suficientemente fuertes o en caso de que no existan tales razones -dada la ausencia de otros deberes de ese tipo-, éstos se convierten en lo que uno debe hacer. ${ }^{8}$ En este caso, aquellos deberes se convierten en deberes concluyentes que por su naturaleza se explican a sí mismos, e.g. el deber de un padre o de una madre hacia su hijo.

Además, existen deberes morales y deberes jurídicos. Los primeros son aquellos deberes en los que impera su origen moral y que, en determinado momento, se perpetúan o continúan como un anacronismo bajo la forma de deberes jurídicos. La presión que respalda el reclamo de conformidad se convierte únicamente en respeto por la ley ${ }^{9}$; este respeto convierte así esos deberes en pautas legales o promulgaciones y por lo tanto en deberes jurídicos. Pero la pregunta más interesante es ¿en qué momento surge este intercambio entre los deberes morales y jurídicos? ¿Cómo puede indagarse si el respeto por la ley vigente no puede acaso rastrearse en la moralidad que inicialmente dio vida a tales deberes y que, de hecho, ese respeto no es otra

\footnotetext{
${ }^{8}$ Tony Honoré, "Must we Obey? Necessity as a Ground of Obligation", Virginia Law Review, Vol. 67, Feb., (1981), p. 48.

${ }^{9}$ Véase Dias, "Jurisprudence", en Obligation and Duty (London: Butterworths and co publishers, Ltd. 1985) 5ª ed., p. 229.
} 
cosa que la moralidad inherente a tales leyes? ${ }^{10}$ Es en esta línea argumentativa en la que la idea de deber u obligación de obedecer el Derecho resulta a la vez interesante y problemática.

Del análisis elaborado hasta el momento se desprenden algunas conclusiones. Simmons afirma que las obligaciones son "requerimientos morales generados por la ejecución de un acto voluntario”. A mi parecer, esto explica que las obligaciones sean debidas, creadas, asumidas o aceptadas. Si Simmons está en lo correcto, en relación con la idea de que las obligaciones son generadas (y en este sentido entiendo que el termino "generadas" excluye la idea de imposición), entonces una obligación no se impone ni posee una relación necesaria con las sanciones. Lo anterior significa en términos habituales, que el temor a la sanción no impone obligaciones y no requiere la imposición de obligaciones. De la definición de Simmons también se deduce lo siguiente: si las obligaciones son requerimientos morales ¿son acaso generados únicamente porque los actos realizados en conformidad con ellos son voluntarios? O bien, ¿es que tales actos son voluntarios porque se ubican dentro de los confines de un requerimiento moral y no de requerimientos jurídicos? Simmons parece no tener una respuesta ante esta pregunta. La razón que encuentro para formular esas dudas reside en mostrar el nivel de distinción que puede trazarse entre los actos voluntarios, generados por los requerimientos morales, y aquellos que son generados por los requerimientos jurídicos, si es que los hay. ¿Pero qué son los requerimientos morales?

Si contestásemos a la pregunta en el sentido de que son obligaciones, en realidad no habremos contestado a la cuestión, se estaría incurriendo en una petición de principio. Una posible respuesta sería afirmar que los requerimientos morales son estándares morales mediante los cuales es posible la realización de un acto esperado, ya que tales requerimientos son aceptados o creados. En otras palabras, que dichos estándares explican la razón del por qué, dentro de unas expectativas determinadas, se afirma que la realización de ciertos actos es aceptada o debida y no impuesta. En suma, que son actos que debemos hacer, i.e., acciones generadas, debidas, aceptadas o creadas mediante estándares adecuados para un ser humano ideal ${ }^{11}$. Todo esto mues-

\footnotetext{
${ }^{10}$ Estas preguntas subrayan una de las controversiales dimensiones del debate acerca de la conexión conceptual entre el Derecho y la moral. Véase el debate entre los profesores Hart y Fuller en Harvard Law Review, vol. 71, (1958); véase, además, Edmond Cahn, The Moral Decision, (1955); Bloom Cooper y Drewry, G., Law and Morality, (1976); Norman Saint JohnStevas, Life, Death and the Law, (1961).

${ }^{11}$ Equiparar el "requerimiento moral” de Simmons con la idea de los estándares morales puede parecer sencillo y directo: sin embargo, puede suscitar malos entendidos. En primer lugar existen muchos estándares en la filosofía moral, ¿cuáles constituyen un requerimiento? En segundo lugar los estándares no tienen una naturaleza estática ya que evolucionan; y si
} 
tra entonces la conexión entre los enunciados de deber y de obligación. Se puede afirmar en ese sentido que existe una relación lógica entre el concepto de "razón" y los enunciados de deber ${ }^{12}$. Podemos concluir que si se da el caso de que alguien deba hacer algo, o que algo deba ser realizado, entonces existen buenas razones para que aquello sea hecho ${ }^{13}$ o para no hacerlo en absoluto.

Llegado este punto, se puede decir que si los enunciados de obligación y de deber son expresables también a través del lenguaje del deber o poseen la misma estructura conceptual que el lenguaje de deberes, entonces podemos concluir que al afirmar que existe una obligación de obedecer el Derecho estamos introduciendo la razón del por qué un ciudadano tiene el deber o la obligación de obedecer el Derecho de un Estado. Esto desvía mi atención hacia el debate en la filosofía del Derecho sobre la obligación de obedecer el Derecho.

\section{¿Existe una obligación de obedecer el Derecho?}

La pregunta acerca de la obligación de obedecer el Derecho ha sufrido un giro muy importante en la historia del pensamiento teórico jurídico. Existen puntos de vista divergentes sobre el tema: por un lado se encuentran aquellos que niegan la existencia de tal obligación, frente a aquellos que afirman contundentemente su existencia y ofrecen pruebas de ello. Primero me ocuparé del punto de vista que afirma que tenemos una obligación de obedecer el Derecho, posteriormente presentare el punto de vista escéptico.

\section{Partidarios de la existencia de una obligación de obedecer el Derecho}

En la literatura contemporánea de la teoría del Derecho, el análisis acerca de la idea de obediencia al Derecho ha recibido un tratamiento notorio

evolucionan y se afirma que son la base del requerimiento moral de acuerdo con Simmons, entonces se sigue que los enunciados de obligación no tienen un carácter estático. En otras palabras, lo que puede servir como base para la obligación puede rechazarse por futuras concepciones. Finalmente existen tres niveles a través de los cuales puede analizarse lo anterior: los estándares que requerimos, aquellos que deseamos, y aquellos que respetamos. Obviamente, hay diferentes niveles de estándares y si los enunciados de obligación se basan en ellos esto puede ser problemático. Entonces ¿cómo avanzar si existe un punto límite en el análisis de la naturaleza de los deberes y la obligación? Mi respuesta es la siguiente: sea lo que sea aquello que los estándares morales invoquen, puede afirmarse con seguridad que los estandartes morales mediante los cuales realizamos un juicio se encuentran necesariamente conectados con la estructura del lenguaje prescriptivo. Es por eso que afirmo que aquellas acciones son generadas a través de dichos estándares y que son posibles ya que son debidos o creados, i.e., constituyen aquello que debemos hacer.

\footnotetext{
12 J.C. Smith, op. cit. p. 35.

${ }^{13}$ Ibíd., p. 59.
} 
en el trabajo de John Austin. Las ideas de Austin acerca de la existencia de la obligación de obedecer el Derecho provienen de su teoría del Derecho. Según John Austin,

“Todo Derecho positivo, o todo Derecho así llamado, es impuesto por un soberano o por un conjunto de personas soberanas al miembro o miembros de la sociedad políticamente independiente en la cual dicha persona o cuerpo es soberana y suprema"14.

De acuerdo con Austin, el soberano es aquel individuo o conjunto de individuos que reciben obediencia habitual de la masa de la sociedad sin que aquellos presten obediencia a una instancia superior. En sus palabras,

"Si un sujeto superior que no debe obediencia a otro semejante, recibe obediencia habitual por parte de la gran mayoría de una determinada sociedad, ese individuo es entonces soberano en tal sociedad, y esa es entonces una sociedad política e independiente" 15 .

Para Austin, la obligación de obedecer el Derecho surge del mandato soberano según el cual algo debe ser hecho o de lo contrario se aplicará una sanción. En otras palabras, la obligación es jurídica, según Austin, dado que "una ley que no establezca obligación alguna es una contradicción en sus

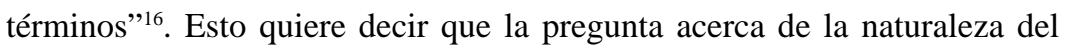
Derecho y de la obligación que genera, tiene su origen en el carácter vinculatorio y coactivo del Derecho. En su famosa frase

"La existencia del Derecho es una cosa, su merito o su demérito es otra. El que lo sea o no, es una pregunta, el que lo sea conforme a ciertos estándares asumidos es una pregunta diferente. Una ley que de hecho existe, es una ley a pesar de que no la aprobemos o a pesar de que varíe en relación con el texto respecto al cual valoramos si la aprobamos o la desaprobamos $[\ldots]^{17}$ Las leyes más perniciosas y por tanto, aquellas que a simple vista parecen oponerse a la voluntad de Dios, han sido y son continuamente reforzadas como leyes por los tribunales judiciales"18.

En resumen, la idea austiniana de la obligación no es únicamente que existe una obligación de obedecer el Derecho, sino que la obligación en cuestión es jurídica y no de otro tipo. Es jurídica, debido a que la ley en cuestión tiene necesariamente el rasgo de una obligación, es decir, es vinculante, y por lo tanto, hablar del Derecho en términos que no impliquen obligatoriedad es caer en contradicción. Más aún, Austin considera que el rasgo

${ }^{14}$ John Austin, “Law as the Sovereing’s Command” en The Nature of Law, M.P. Golding (ed.) (New York: Random House, Inc., 1966), p. 95.

${ }^{15}$ Ibíd., p. 94.

${ }^{16}$ p. 96.

${ }^{17}$ p. 95.

${ }^{18}$ p. 96. 
principal de esta obligación es el dolor que puede inflingirse a un individuo en caso de desobediencia. Dicho muy brevemente, la obligación para Austin es jurídica y por tanto no es moral ni prudencial.

Los críticos de Austin consideran que en el trabajo de este autor hay un error fundamental. H.L.A. Hart -quien se basa en la teoría austiniana de la obligación-, postula que la teoría de Austin es incapaz de proveer una imagen clara de la obligación. La crítica de Hart se dirige hacia dos puntos concretos: Hart rechaza la naturaleza del Derecho en los términos establecidos por Austin y critica la idea de obligación que de ella se deriva. En primer lugar, definir el Derecho como mandato del soberano implica mostrar una visión incompleta de la naturaleza del Derecho. El modelo de Austin elimina por completo aquellas reglas que autorizan o confieren poderes y que prácticamente, no son reducibles a mandatos. Hart critica además el modelo austiniano de la naturaleza del Derecho ya que refleja únicamente relaciones de tipo vertical, es decir, mandatos de un soberano a un súbdito; existen leyes según Hart que configuran una relación horizontal ${ }^{19}$.

La crítica de Hart, a partir de su teoría de la obligación, no consiste en negar la existencia de una obligación de obedecer al Derecho, sino que defiende que ésta no debe entenderse en términos coactivos. Está de acuerdo con Austin en que la obligación de obedecer el Derecho es jurídica, i.e., que se relaciona con el aspecto interno de las reglas. Para Hart, sin embargo, el análisis de la obligación ofrecido por Austin claramente exagera la relación entre tener una obligación y verse obligado a obedecer. Hace una analogía entre la propuesta de Austin y el caso de las amenazas de un hombre armado, ya que Austin considera que no existe un orden jurídico si sus reglas no imponen un castigo en caso de desobediencia ${ }^{20}$. Además, la teoría de Austin presenta el punto de vista según el cual no existe obligación para un individuo si no existe la posibilidad de la amenaza o la coacción. Esta imagen no se percata de las razones por las que la gente obedece o debe obedecer, y por ello, es insuficiente para esclarecer la realidad práctica subyacente a la relación entre un sistema jurídico y sus ciudadanos. ¿Cuáles son entonces las ideas de Hart acerca de la obediencia al Derecho?

De acuerdo con Hart, la teoría de la obligación se explica mediante expresiones como "deber", "estar vinculado", "tener un deber" etc., que están relacionadas con el aspecto interno de las reglas. En sus palabras,

\footnotetext{
${ }^{19}$ Ver, Hart, H.L.A. "Positivism and the Separation of Law and Morals", Harvard Law Review, vol. 71, (1958), pp. 600-606.

${ }^{20}$ Hart, H.L.A. "Obligation and Coercion" en The Nature of Law, M.P. Golding (ed.) (1966), pp. 104-106.
} 
"Si tenemos la obligación de hacer algo estamos en algún sentido vinculados a hacerlo, y ahí donde estamos vinculados estamos en algún sentido constreñidos"21.

En otras palabras, debemos hacerlo porque tenemos la obligación de hacerlo. Dada esta explicación, ¿qué es aquello que perfila nuestra comprensión acerca del deber jurídico?

En El concepto de Derecho, Hart expone algunos factores que determinan la obligación de un individuo de obedecer el Derecho. En primer lugar, la existencia de reglas sociales que configuran cierta clase de acciones como estándares de comportamiento; en segundo, que la función distintiva de un enunciado tal consiste en aplicar una regla a un cierto individuo llamando su atención en el hecho de que su conducta está regulada por un estándar ${ }^{22}$. Sin embargo, no todas las reglas sociales generan obligaciones para el individuo.

Posteriormente, Hart explica que una regla particular, por ejemplo $X$ impone una obligación, si, y sólo si, posee las siguientes características. Primero, si $X$ establece que hay una demanda social de conformidad; segundo, si $X$ es necesaria para el sustento de la vida social; tercero, si $X$ implica renuncia y sacrificio ${ }^{23}$. Sin embargo, de acuerdo con Hart, lo que determina nuestra concepción acerca del deber hacia el Derecho es la idea de presión social; esa presión imprime en el individuo la idea de que la sociedad demanda su conformidad con la regla. Dicha presión según Hart asegura la obediencia al Derecho.

Hart sostiene que tales obligaciones son similares a las que se derivan de una promesa. En ambas puede hablarse de obligaciones creadas debido a su “dependencia de una práctica vigente del grupo" por tanto hay una "posible independencia del contenido” y del uso de la coacción ${ }^{24}$. ¿Es necesaria la coacción en relación con las obligaciones surgidas de una promesa, y, por extensión, respecto de la obligación de obedecer el Derecho? Hart así lo cree. ¿El contenido de ciertas reglas conlleva alguna diferencia? Hart no lo niega. Para él, lo importante es "el seguimiento de un procedimiento por el sujeto apropiado en las circunstancias apropiadas”25.

En conclusión, lo que podemos extraer del análisis de Hart acerca de la obediencia al Derecho es que ha tenido éxito solamente en la explicación

\footnotetext{
${ }^{21}$ Ibíd., p. 104.

${ }^{22}$ Hart, H.L.A. The Concept of Law, (Oxford: Clarendon Press, 1961), p. 83.

${ }^{23}$ Ibíd., pp. 84-85.

${ }^{24}$ Hart, H.L.A., "Legal and Moral Obligation” en A.I. Melden (ed.) Essays in Moral Philosophy, (Seattle: University of Washington Press, 1958), p. 103.

${ }^{25}$ Ibíd., p. 102.
} 
acerca de cómo los individuos perciben las reglas cuando las aceptan como estándares, pero no explica por qué ellos aceptan ciertas reglas como guías para su conducta ${ }^{26}$. Es el "por qué" lo que explica cabalmente que la gente considere que el Derecho deba obedecerse y deba, por tanto, ser aceptado por ellos como constitutivo de un estándar para su conducta ${ }^{27}$. Al analizar la estructura del lenguaje acerca del deber, se afirmó que la respuesta al "por qué" frecuentemente acompaña tales enunciados. Entonces, si Hart se proponía explicar el deber de obediencia a la ley, esa explicación debe tener en cuenta por qué es vinculatoria o por qué tales leyes son obligatorias.

A juicio de R. J. Bernstein, la explicación de Hart fue insuficiente para demostrar la diferencia entre las reglas que crean o imponen obligaciones y las que no lo hacen. Como prueba de ello muestra aquellos estándares que, a pesar de no crear obligaciones, reflejan una presión social severa en relación con aquellos que se desvían de ellas ${ }^{28}$. Y más aún, la falta de énfasis por parte de Hart en la presión social como fuerza vinculante de la obligaciones se aproxima a la idea de que "la gente impone presión social sobre otras para que se comporten de determinada manera dada la existencia de una obligación" y de que una "obligación no existe porque ciertos individuos ejercen presión social”29. La presión social impuesta por los individuos no determina la existencia de una obligación; es concebible que ciertos individuos ejerzan presión social, e insistan en que se obtenga un mínimo estándar de comportamiento, sin que tal estándar lleve aparejado un fuerte componente de obligación.

Por su parte, Henry Hart señala que la obligación de obedecer el Derecho es jurídica y que el incumplimiento de una ley permite calificar al infractor como criminal. De acuerdo con Hart, "el incumplimiento voluntario o involuntario de una obligación jurídica provee una base para la culpa, lo que justifica calificar a los infractores como delincuentes" ${ }^{30}$. Este argumento no considera las razones por las cuales un individuo puede actuar en contra de lo establecido por una ley; y argumentar que un individuo no puede justificar su actuar ilícito implica olvidar algunos de los rasgos sobresalientes de las prescripciones constitucionales acerca de las reivindicaciones en contra del Estado.

\footnotetext{
${ }^{26}$ J.C. Smith, op. cit., p. 28.

${ }^{27}$ Ibíd.

${ }^{28}$ Bernstein, R.J. “Prof. Hart on Rules of Obligations”, Mind, vol. 73, (1964), p. 563. Como ejemplo el Prof. Bernstein propone la desnudez.

${ }^{29}$ J.C. Smith, op. cit., p. 33.

${ }^{30}$ Henry Hart, "The Aims of the Ciminal Law", Law and Contemporary Problems, vol. 23, (1958), pp. 401, 418.
} 
Tony Honoré adopta un argumento distinto. En su opinión puede decirse que un individuo tiene la obligación de obedecer el Derecho si cada miembro de una sociedad, en la que la pertenencia es forzosa, debe satisfacer los requerimientos de otros miembros cuando se le presentan bajo la forma constitucional adecuada ${ }^{31}$.

En opinión de estos autores, el mero hecho de que una ley ordene o prohíba alguna acción es condición necesaria y suficiente para afirmar, no solamente que existe obligación de obedecer el Derecho, sino que, de hecho, aquellas leyes imponen obligaciones a los afectados y que, en ese sentido, se puede afirmar que la ley es vinculante; la pregunta acerca del contenido de las leyes debe siempre examinarse con independencia de cuál sea la obligación de un individuo. Estas consideraciones son relevantes para un escrutinio crítico del punto de vista según el cual, hay obligación de obedecer el Derecho y que dicha obligación es jurídica, es decir, que deriva de las reglas jurídicas. Sin embargo, hay quienes sostienen que no tenemos obligación de obedecer el Derecho.

\section{Perspectivas escépticas acerca de la obligación de obedecer el Derecho}

La pregunta que incomoda a estos filósofos escépticos es la siguiente ¿el hecho de que el Derecho requiera algo es por sí mismo una condición necesaria y suficiente para hacerlo? Josep Raz, en las páginas iniciales del capítulo "Obligación de obedecer el Derecho" de su libro "La autoridad del Derecho"32 afirma que no existe obligación de obedecer el Derecho. El profesor A. Woozley en Law and obedience opina firmemente que explicar la razón por la cual una ley es obligatoria diciendo "porque así lo establece el Derecho” no constituye razón alguna.

En opinión de Woozley, "si líderes políticos y jefes de policía se impusieran, nosotros creeríamos que una razón de peso (posiblemente la principal, sino es que la única razón) para obedecer la ley sería simplemente porque es tal ley. De hecho, exceptuando determinada clase especial de leyes, esa no es razón alguna”33. Que una ley ordene o prohíba la realización de cierta conducta puede no constituir por sí misma una razón suficiente para obedecerla. Una ley simplemente establece que algo debe hacerse, el por qué debe hacerse simplemente está fuera del alcance del Derecho.

Alan Simmons también se adhiere al punto de vista según el cual no hay un deber prima facie de obedecer el Derecho. Para Simmons, los gobiernos

${ }^{31}$ Op. cit., p. 44.

32 Josep Raz, The Authority of Law. Essays in Law and Morality, (Oxford: Clarendon Press, 1979), p. 233.

${ }^{33}$ A.Z. Woozley, Law and Obedience, (1979), p. 72 
no tienen normalmente derecho a ser obedecidos por sus ciudadanos, no tienen derecho a forzarlos a obedecer, o a castigarlos en caso de desobedien$\mathrm{cia}^{34}$. En esa línea escéptica, M.B.E. Smith sostiene que no hay obligación prima facie de obedecer el Derecho ${ }^{35}$. Esto quiere decir que siempre hay razones para mostrar que no hay tal presunción en favor del deber de obediencia y que hay razones fuertes para mostrar que alguien no está obligado a hacer lo que el Derecho establece. Richard Wasserstrom, por su parte, rechaza la idea según la cual si un individuo actúa ilegalmente no pueden existir razones sólidas para justificar su actuar ilícito.

Las anteriores son posturas escépticas acerca de si el mero hecho de que una acción sea ordenada o prohibida por el Derecho constituye, en sí mismo, una condición necesaria y suficiente para hacer o abstenerse de hacer lo que el Derecho prescribe. Sin embargo, viendo las cosas desde otra perspectiva, hay excepciones a estas conclusiones escépticas. Josep Raz, por ejemplo, afirma que aquel sujeto que en realidad respeta las leyes de un Estado está constreñido a obedecer. Para este autor, el respeto hacia un sistema jurídico genera obligaciones; ¿pero en que sentido puede decirse que el respeto es una condición necesaria y suficiente para generar un deber de obediencia? Claramente hay muchos casos en los que un individuo muestra una actitud de respeto a un sistema jurídico sin estar obligado a hacer lo que este ordena; es posible mostrar respeto, pero no es siempre cierto que esto genere obligaciones. El respeto no es necesario para generar un deber prima facie; de hecho, puede pensarse que la falta de respeto hacia las leyes es un modo para denunciar errores fundamentales en un sistema jurídico determinado. El deber hacia otros ciudadanos se funda en la interdependencia y no en la amistad, de otro modo seria ventajosa la falta de respeto ${ }^{36}$.

Woozley, por su parte, admite que solamente cierta clase de leyes vinculan a hacer lo que el Derecho establece y que esto constituye una razón suficiente. Por ejemplo, las leyes que regulan el voto ${ }^{37}$. Para que un individuo vote, y para que lo haga en el sentido adecuado, a uno le corresponde considerar la ley que regula el voto como suficientemente fuerte para explicar por qué la ley es obedecida; excepto, cuando uno opta por no votar, lo que significa que hay razones morales de peso para no hacerlo. Todos estos filósofos, a pesar de su postura escéptica, admiten que hay razones morales independientes para hacer lo que el Derecho exige. Sin embargo, la

\footnotetext{
${ }^{34}$ Simmons, op. cit., pp. 193-195.

${ }^{35}$ M.B.E. Smith “Is there a Prima Facie Obligation to Obey the Law?”, Yale Law Journal, vol. 82, (1973), p. 950.

${ }^{36}$ Ver Tony Honoré, op. cit. p. 50.

${ }^{37}$ Op. cit. p. 6.
} 
cuestión importante es: ¿hacia dónde y a qué fin nos conducen estos puntos de vista en relación con la discusión acerca del problema de la obediencia al Derecho?

Que las obligaciones sean morales o jurídicas depende de lo que signifique decir que una obligación es moral o jurídica. La obligación moral muestra la obediencia a una ley como algo externo a ella. En otras palabras, aquello que explica adecuadamente que una ley sea moralmente vinculante respecto a un individuo es que ésta consigue el deseado fin de la existencia humana, i.e., la felicidad a la luz de lo que aquella ley considera justificado. Una ley inmoral, es decir, aquella que fracasa en el intento de conseguir el fin deseado de la existencia humana, no conlleva obligación alguna. Este argumento no quiere decir que toda regla moral se convierta en una regla jurídica, sino que cualquier regla jurídica que sea creada con la pretensión de vincular moralmente debe admitir el mínimo estándar de toda regla moral. En otras palabras, el "deber” de una regla jurídica es perfilado por un deber moral, en el sentido de que si es el caso que un individuo esté legalmente obligado a hacer $X$, entonces es el caso que debe hacerlo en un sentido mo$\mathrm{ral}^{38}$. Esto se acerca al pensamiento del Derecho natural. La famosa frase de Tomás de Aquino y de Agustín de Hipona según la cual "una ley injusta no es ley”, recoge, en algún sentido, el punto de vista anterior. La misma idea es destacada en La moralidad del Derecho del Profesor Lon Fuller, quien argumenta que hay una moralidad que hace posible el Derecho y que lo hace vinculante u obligatorio. Esto es lo que denomina "la moral interna del Derecho" y la "moral externa al Derecho"39. El último aspecto se refiere a la moral que hace posible el Derecho, i.e., algunos requerimientos morales para la existencia de un orden o sistema jurídico. El primero es descrito por Fuller como aquellos principios morales respecto a los cuales debe conformarse toda creación del Derecho. Estos aspectos morales, de acuerdo con Fuller, constituyen la base de la obediencia al Derecho. Para él, la obligación no puede ser jurídica porque no puede fundarse únicamente en el Derecho. En sus palabras:

"Que el Derecho no pueda estar fundado en el Derecho puede entenderse en un doble sentido. En primer lugar, la autoridad para crear Derecho debe estar respaldada por actitudes morales que le confieren la competencia que reclama para sí mismo. En este caso, nos encontramos frente a la moralidad externa al Derecho, la moralidad que lo hace posible [...] No puede existir Derecho hasta

\footnotetext{
${ }^{38}$ J.C. Smith, op. cit., p. 6.

${ }^{39}$ Lon Fuller, The Morality of Law, (Connecticut: Yale University Press, 1964), pp. 152184. Véase también "Positivism and Fidelity to Law. A Reply to Prof. Hart", Harvard Law Review, vol. 71, (1958), pp. 630-672.
} 
que nuestro monarca esté preparado para aceptar la moralidad interna del Derecho" ${ }^{40}$.

El mismo punto de vista se encuentra en la obra de John Finnis. Siguiendo la tradición del Derecho natural, Finnis sostiene que la obligación de obedecer el Derecho surge en la medida en que la ley en cuestión contravenga o refuerce lo que él llama “principios básicos” y "razonabilidad práctica”. Las leyes que contravengan estos principios serán calificadas como injustas porque no permiten alcanzar el bien común; mientras que aquellas que los refuerzan o se aproximan a ellos serán justas. Por tanto "la autoridad moral del Derecho depende [...] de su justicia o por lo menos de su capacidad para asegurar la justicia”41. Aquel sentido de justicia no es para Finnis, dirigido a uno mismo sino dirigido a otros, es decir, tiene que ver con las relaciones hacia otros individuos ${ }^{42}$. Es un deber dirigido a otros tal como el deber de un gobernante hacia sus súbditos, es decir, un deber que asegura la aplicación de leyes justas. Una obligación tal se dirige a otros y permite entender que la obediencia al Derecho no es prudencial. En opinión de Finnis, la obediencia prima facie al Derecho es una obligación moral una vez que pueda decirse que las leyes son justas, es decir, cuando se dirigen hacia la obtención del bien común. La importancia de ese punto de vista se muestra en el siguiente pasaje:

"La autoridad, hablando estrictamente, no tiene derecho a ser obedecida pero tiene la autoridad para emitir órdenes y crear leyes moralmente obligatorias, teniendo la responsabilidad de imponerlas mediante la amenaza de la fuerza. Posee esta autoridad en interés del bien común [...] Entonces, si usa esa autoridad para crear leyes en contra del bien común o en contra de cualquier principio básico de razonabilidad práctica, aquellas leyes en su conjunto carecen de la autoridad que de otro modo tendrían por su propia naturaleza”33.

A partir del análisis de que existe obligación de obedecer el Derecho, y de que la base de tal obligación es moral, dicho en términos simples, se explica la idea de que la obligación de obedecer el Derecho deriva de la conformidad de una regla jurídica con una norma externa. En otras palabras, significa que el contenido moral de la ley define o determina si se genera una obligación de obedecer el Derecho. Sería completamente incorrecto etiquetar dichas ideas como estricto pensamiento de Derecho natural. Si bien, se puede decir que la doctrina del Derecho natural tiene una tendencia hacia tales puntos de vista, hay, sin embargo, algunos positivistas contemporáneos

\footnotetext{
${ }^{40}$ Lon Fuller, "Positivism and Fidelity to Law" op. cit. p. 645.

${ }^{41}$ John Finnis, Natural Law and Natural Rights, (Oxford: Clarendon Press, 1980) p. 260.

${ }^{42}$ Ibíd., p. 161.

${ }^{43}$ Ibíd., pp. 359-360.
} 
que poseen esta inclinación. Joseph Raz es uno de los que me vienen a la memoria. Raz afirma terminantemente que no hay obligación de obedecer el Derecho, pero atenúa esta conclusión escéptica añadiendo como excepción que existen razones morales independientes para hacer lo que el Derecho ordena o exige.

¿Qué tan sólida es la tesis según la cual la obligación de obedecer el Derecho se funda en razones morales o en el contenido de la ley? En muchos casos, aquellos que se oponen a la idea de que la obligación de obedecer el Derecho es moral quieren evitar llegar a la conclusión de que hay una conexión necesaria entre Derecho y moral. En otras palabras, lo que se quiere evitar es sostener que no hay una línea clara que divida y separe aquello que el Derecho es de aquello que debe ser. Éste es el punto de vista que los positivistas jurídicos quieren aclarar, es decir, la tesis de la separación. La tesis de la separación como la concibe el Prof. H.L.A. Hart afirma que "en ningún sentido es necesariamente verdad que los normas jurídicas reproducen o satisfacen ciertas exigencias de la moral, aunque de hecho suele ocurrir así” ${ }^{4}$.

$\dot{¿}$ Se incurre en una inconsistencia lógica si se suscribe por un lado la tesis de la separación y por el otro se afirma que el Derecho debe admitir un mínimo contenido moral o bien, que la obligación de obedecer el Derecho es moral? Si se acepta que el individuo es un agente moral, entonces la idea de que su obligación se funda en razones morales no es errada. Desde el punto de vista teórico como desde el punto de vista práctico esto puede sostenerse. Una ley que regule una cuestión que se reconozca como propia de la moral genera sin duda una obligación de obediencia dependiente del grado de moralidad que posea; tal obligación se verá fuertemente acentuada en la medida en que sea conforme con la moral. Y cuando existe silencio con respecto a un asunto moral estará dentro de los confines de la razón afirmar que la idea de obligación moral de obedecer es una pregunta abierta. Esta es la distinción que debemos mantener.

¿Qué sucede entonces con la obligación jurídica? Que la obligación sea jurídica conlleva la idea de que la obediencia al Derecho es interna al procedimiento de creación de las leyes. "La fuente de la obligación jurídica", sostiene Smith, "se deriva del poder autoritativo-coactivo por el cual la ley fue dictada y no del contenido del Derecho"45. Un elemento importante de dicho poder autoritativo es sin duda la coacción, este punto de vista puede describirse entonces como teoría coercitiva de la obligación. A juicio de

${ }^{44}$ Hart, H.L.A. The Concept of Law, (1961), p. 181. [Trad., esp. de Genaro R. Carrió, El Concepto de Derecho, Abeledo-Perrot, Buenos Aires, 1985, p. 230].

${ }^{45}$ Smith, op. cit., p. 7. 
Smith: "La coacción está relacionada con los medios y no con los fines, en consecuencia, aquellas teorías que suscriben una teoría coactiva de la obligación serán positivistas. La coacción esta relacionada con mandatos y los mandatos, generalmente, son expresión de la voluntad más que de la razón ya que no proveen lógicamente una justificación de la manera en que sí la provee apelar a la razón”46.

A partir de lo anterior, ¿̇no se sigue que la idea según la cual la obligación de obedecer el Derecho es jurídica puede sujetarse a crítica? Pero suponiendo que la existencia del Derecho y sus exigencias sean una razón para afirmar que un individuo tiene la obligación de obedecer, entonces, desde esa base, es obvio que eso no constituye una razón sino una petición de principio. Más aún, la obligación jurídica, tal y como fue presentada, conlleva la creencia de que las obligaciones no existen, o bien, de que no son creadas para un individuo cuando no hay posibilidad de que sea sancionado y condenado ${ }^{47}$.

De lo anteriormente expuesto, acerca del debate entorno a la existencia de una obligación de obedecer el Derecho y lo que esto significa, puede afirmarse que se sitúa en medio del terreno de aquellos que afirman que es moral y de aquellos que afirman que es jurídica. En lo que resta de este trabajo aportaré una imagen de la obligación tal y como resulta de la esencia de la práctica de la revisión judicial.

\section{Perspectiva teórica acerca de la doctrina de la revisión judicial}

En la teoría del Derecho, la doctrina de la revisión judicial es un tema que ha suscitado una gran controversia. La polémica se centra, a grandes rasgos, en la legitimidad, justificación o fundamento de los presupuestos que subyacen a las estipulaciones, práctica y ejercicio de esta doctrina. Desde una posición moderada, es posible sostener que la legitimidad del control de leyes es frecuentemente cuestionada en todo caso importante que inquieta a un gran número de individuos. Desde una posición extrema, sin embargo, es considerada antidemocrática porque frustra la voluntad popular al anular la labor de sus representantes previamente elegidos, esto es, de la administración y de la legislatura democrática. ${ }^{48}$

\footnotetext{
${ }^{46}$ Ibíd.

${ }^{47}$ Theodore Benditt, Law as Rule and Principle, (Inglaterra: The Harvester press Ltd., 1978), p. 118.

${ }^{48}$ Sostiene esta idea Harry H. Wellington, "The Nature of Judicial Review”, Yale Law Journal, vol., 91, (1982), pp. 486-487. En mi opinión esta crítica es incorrecta. La revisión judicial, cada vez que se ejerce, no requiere anular una ley o decreto del ejecutivo. Cuando esto sucede se efectúa siguiendo un procedimiento específico y determinado. Es verdad que los jueces son designados y seleccionados pero eso no contradice que la designación y selec-
} 
Es en estos términos que el fundamento de la práctica es cuestionado por promover la idea de un poder judicial omnipotente. Más aún, se percibe la práctica de la revisión judicial como un acto de usurpación. Por ejemplo, en los Estados Unidos se suele afirmar que dicha doctrina no es un poder constitucionalmente reconocido, y por tanto, es observado como un intento de auto-atribución judicial de poder.

Pero a pesar de la red de controversias en que está envuelta la doctrina de la revisión judicial, algunos han visto en su esencia un modo para promover una democracia constitucional activa. En otras palabras, la revisión judicial es importante como medida correctiva en contra de los excesos políticos y el abuso del poder. Además, la democracia se presenta como uno de los medios idóneos para atenuar los excesos de las esferas políticas más permeables del gobierno, i.e., el legislativo y el ejecutivo. Así mismo, esta institución se percibe como el último bastión en el aseguramiento, salvaguarda y promoción de los derechos y libertades de los ciudadanos en contra del despotismo del poder legislativo y del ejecutivo.

Cuando se habla de la revisión judicial se habla también de la validez de las leyes. El ejercicio del control de las leyes está relacionado con el poder de un Tribunal para revisar y declarar la inconstitucionalidad de una ley dictada por el legislativo. En concreto, se declara que una específica ley del órgano creador es nula, ya sea en su totalidad, o en parte, por contravenir ciertas disposiciones constitucionales. Considerando que la ley proviene del órgano creador de Derecho, es decir, de la legislatura que controla y regula el día a día de las vidas y actividades ciudadanas, se sigue que cualquier acto que altere o afecte, desde el punto de vista de la Constitución, dicho control ejercido por el Parlamento, tendrá importantes consecuencias en relación con la obligación de los ciudadanos de obedecer tales leyes.

Partiendo de esta perspectiva teórico-constitucional, se sigue que una ley que contravenga los lineamientos constitucionales será inválida y carecerá de efectos, es decir, no será vinculante. De esto se sigue "[que] no impondrá deberes, que no creará derechos, ni protegerá a aquellos que asumen que deben obedecerla" ${ }^{49}$. Es ésta la posibilidad que quisiera explorar como relevante en relación con la discusión acerca de la obediencia al Derecho. Se puede objetar que, a la luz del debate teórico existente, la revisión judicial

ción se realice según cierto procedimiento democrático. Por ejemplo, en los Estados Unidos el presidente propone candidatos para puestos judiciales y, posteriormente, estos son presentados ante el Congreso para su aprobación. Lo mismo puede decirse en el caso del nombramiento de puestos judiciales durante la Segunda República Nigeriana. Hay casos en donde los jueces son elegidos mediante elección popular, aunque no en el mismo sentido que son nombrados los representantes de otras instancias del gobierno.

${ }^{49}$ Horace Davis, op. cit., p. 17. 
carece de relación con el problema de la obediencia al Derecho, o bien, que el control de las leyes prueba la inexistencia de una obligación de obedecer una ley declarada inconstitucional.

En lo que sigue, intentaré señalar las objeciones que surgen respecto al significado de la revisión judicial desde la óptica del problema de la obediencia al Derecho. La revisión judicial, cuando es ejercida adecuadamente, permite explicar por qué una ley del órgano creador de Derecho es nula e inválida, y por qué un individuo, que busca una solución acudiendo a un Tribunal, no se encuentra bajo la obligación de obedecer tal ley. En otras palabras, una ley declarada inconstitucional no impone y no genera obligaciones a los afectados o aquellos que se supone debieran verse obligados.

Se suele considerar que la fuerza vinculante del Derecho es una cuestión de - o que da lugar a- obligaciones. En otras palabras, se pretende que las obligaciones jurídicas generadas por una ley sean distintas de las obligaciones morales. Esto quiere decir que aquellos que afirman que la obligación de obedecer el Derecho es jurídica aceptan que el mero hecho de que algo sea ordenado o prohibido por la ley constituye una condición necesaria y suficiente para hacer, o abstenerse de hacer, lo que el Derecho prescribe. Esto querría decir que la obligación de obedecer el Derecho es independiente del contenido de una determinada ley.

Pero el poder de revisión ejercido por los jueces subraya precisamente que la fuerza vinculatoria de las leyes no es una razón suficiente para sostener que los ciudadanos tienen la obligación de obedecer la ley o las leyes en general. La posibilidad de revisar y anular las leyes que infringen derechos morales como la libertad de conciencia, la libertad de pensamiento, de asociación, de trabajo y profesión, el derecho de participación política, la libertad para seguir planes de vida etc., ofrece un argumento convincente en contra de la idea de que la obligación de obedecer el Derecho surge simplemente porque la ley es la ley. De hecho, esgrimir tal argumento implicaría incurrir en una petición de principio.

Si una ley genera obligación porque es la ley, y si existe la posibilidad de que dicha norma, en relación con su contenido, pueda sujetarse a revisión, -i.e., para que se establezca que su contenido es conforme, o bien para que se establezca que es preciso apartarla porque su contenido no toma en cuenta los derechos fundamentales-, de ello se sigue que las obligaciones que derivan de una ley no son meramente jurídicas sino que se trata de una obligación derivativa i.e., que depende del contenido. Éste es otro modo de decir que la idea de conformidad de las leyes con respecto a un estándar dado o asumido es un criterio fundamental en el aparato creador de leyes. Esto es, en términos claros, lo que la revisión judicial en su esencia y justificación constitucional pretende establecer y afirmar. 
Este argumento no olvida que puede abusarse del ejercicio de la revisión judicial así como también de los procedimientos legislativos a través de los cuales son creadas las leyes. Pero, por ahora, lo que he intentado dejar claro y establecer por medio de mis argumentos, es que cuando el poder de revisión es adecuadamente ejercido dentro de la estructura democráticoconstitucional permite corregir el error inherente a la idea de que sea cual sea el requerimiento surgido de un proceso legislativo éste genera obligaciones. En otras palabras, se rechaza el punto de vista de que tal ley intenta ser vinculante sea cual sea su intención y que tal fuerza vinculante puede calificarse en términos de obligación hasta el punto de que un ciudadano esté forzado a obedecer tales leyes. Lo que la revisión judicial permite, en esencia, es un modo de cultivar y establecer un sentido compartido de justicia y el bien común que son los componentes necesarios de las leyes y otras promulgaciones. Como afirma Samuel Freeman,

"La práctica de los tribunales consistente en justificar sus decisiones recurriendo a opiniones razonadas, hace públicas (en un modo en que no lo logra el procedimiento legislativo) las razones y propósitos detrás de la legislación al examinar las leyes a la luz de la Constitución. Al ratificar la legislación en contra del desafío constitucional la Corte intenta legitimar las leyes mostrando su consistencia con la Constitución”" ${ }^{50}$.

Samuel Freeman apunta también al fundamento moral inherente a la autorización para crear leyes y el sentido de justicia que se espera sea reflejado en todo intento de creación de leyes. En sus propias palabras, Samuel Freeman opina que los tribunales a través de la práctica de la revisión judicial,

"Demuestran públicamente que las leyes no son excesivamente coactivas sino acordes con la libertad democrática. Y al calificar una ley como inconstitucional los tribunales no solamente revisan los fallos legislativos acerca de la justicia, sino que proveen, además, razones constitucionales acerca de estos fallos. En ambos sentidos, la revisión judicial contribuye al establecimiento de una lectura pública de la Constitución y de sus fundamentos morales al examinar las leyes a la luz de esos principios" ${ }^{\text {"1 }}$.

Una interpretación correcta de lo anterior, así como del conjunto de las ideas antes expuestas acerca de la conexión entre revisión judicial y obediencia al Derecho es, desde mi punto de vista, la siguiente: cualquiera que esté obligado a obedecer una ley coherente con la Constitución puede justificadamente rehusarse a obedecer una ley declarada inconstitucional o tiene la obligación de desobedecer una ley declarada inconstitucional. El reverso de

${ }^{50}$ Samuel Freeman, “Constitutional Democracy and the Legitimacy of Judicial Review”, Law and Philosophy, vol. 9, (1990-91), p. 365.

51 Ibíd. 
la anterior afirmación puede ser algo como lo siguiente: cualquiera que no sea inmune a la obligación de obedecer una ley, cuya validez constitucional no ha sido ni confirmada ni rechazada por el Tribunal, tiene la obligación de obedecer una ley que ha sido declarada constitucionalmente válida. Este caso no puede darse cuando se abusa del poder de revisión o cuando éste es claramente mal ejercido. Hay determinados casos en donde puede claramente sostenerse que los tribunales actúan a la luz de los principios evidentes y palpables de la libertad democrática. En una situación tal, un individuo tiene obligación de obedecer una ley que es constitucionalmente válida. Pero la pregunta significativa es ¿qué tan verdadero es este punto de vista o tesis?

Mi argumento a favor de esa idea es que la Constitución, que funciona como un criterio para evaluar la validez de la legislación, representa un punto central de acuerdo entre individuos racionales y autointeresados. Este acuerdo es lo que Samuel Freeman denomina "un precompromiso compartido". En opinión de Freeman, dicho acuerdo no es un compromiso nacido de un conflicto de intereses fundamentales, sino que es una representación de "un interés compartido de los ciudadanos democráticos por mantener las condiciones de su igual soberanía”². Además, de acuerdo con Freeman, ese "acuerdo refleja su aceptación compartida y su compromiso con el mantenimiento de su posición de igualdad respecto a la libre persecución de sus fines”33. La elaboración de una Constitución que incluya los elementos básicos inherentes a los términos de su acuerdo, perfecciona este "precompromiso" y "aceptación compartida". Por esto se requiere la creación de "instituciones políticas que se limiten en los términos de este acuerdo. La revisión judicial, como uno de los tantos rasgos de esa Constitución, es parte del preacuerdo de los ciudadanos de una democracia hacia formas sociales justas" ${ }^{4}$.

En tanto la Constitución incluya los términos de este acuerdo entre individuos racionales y autointeresados, y en tanto reconozca que el poder y autoridad (ya sea directa o indirecta) para enmendar esa Constitución esté en sus manos, es evidente que se puede afirmar que los términos del acuerdo constituyen un precompromiso compartido. Entonces, cuando la legislación democrática es confirmada por los tribunales como constitucionalmente válida, dentro de la estructura de esa opción democrático-constitucional, ésta se convierte en lo que ellos aceptan como obligatorio. "La voluntad popular tiene su expresión más clara y original en una democracia constitucional. Y nada en ese acuerdo exige que se delegue en aquellos con autoridad para

\footnotetext{
52 Ibíd., p. 356.

53. Ibíd.

54 Ibíd.
} 
hacer las leyes ordinarias la autoridad final para decidir la naturaleza de las condiciones constitucionales que determinan la validez de tales leyes"55. Las obligaciones surgidas de esta opción constitucional son obligaciones aceptadas voluntariamente, debidas y creadas; no son impuestas.

Es en este sentido que la doctrina de la revisión judicial, en su práctica y en su esencia, se relaciona con la idea y el concepto de obediencia al Derecho en la forma en que ha sido concebida en este trabajo. De manera sencilla, se puede afirmar entonces que un individuo o ciudadano de una sociedad democrática -que posea un sentido de aceptación y compromiso compartidos por mantener un estatus igual a los otros en el libre alcance de sus fines e intereses en un acuerdo con otros en igualdad de estatus dentro del marco de un arreglo constitucional-, tiene, en términos de ese acuerdo, la obligación de obedecer dichas leyes una vez que pueda afirmarse que son válidas en los términos de aquel arreglo y marco del cual forma parte.

Con el fin de confirmar los términos de esta obligación de obedecer el Derecho, un individuo acude ante el Tribunal cuando se contravienen los términos de ese acuerdo y las especificidades del compromiso documentados en la forma de una Constitución. Lo que hacen los jueces cuando ejercitan dicho poder sobre las leyes es dar razones ya sea, de que esa ley es acorde con los ideales democráticos resguardados en la Constitución, o bien, que esas leyes son contrarias al estándar constitucional de justicia. En ambos casos, la revisión judicial examina las leyes a la luz de los términos del acuerdo subrayados en la Constitución.

Por lo tanto, cuando los jueces ejercitan el poder de revisión se obtiene cualquiera de estos resultados: o se declara la constitucionalidad de la ley, o bien, se declara su inconstitucionalidad. En el primer caso, la norma en cuestión genera una obligación debida y no impuesta al sujeto destinatario; si se da el segundo, la norma no cuenta como vinculante ya que deja de ser una ley válida, i.e., "[es] Derecho muerto"; como consecuencia, esa ley no será aplicable mediante el uso de la fuerza. En ambos casos, la idea de obediencia al Derecho se manifiesta a través del ejercicio de la revisión judicial. Cuando se confirma la constitucionalidad de una ley se hace por una razón determinada que remite a la presencia de un factor vital necesario en todo intento de creación de leyes, por tanto, queda cerciorada su constitucionalidad. Y cuando sucede lo opuesto no se puede hablar de obligación debido a la ausencia de factores vitales necesarios para la idea del Derecho y su creación. Es la "presencia o ausencia de estos factores vitales" acentuados a través de la revisión judicial, lo que atrae mi atención y lo que reafirma mi posición acerca de que la doctrina del control judicial esta conectada con la idea de

${ }^{55}$ Ibíd., p. 360. 
obediencia al Derecho. La revisión judicial da respuesta al hecho de que cuando algo es ordenado o prohibido por el Derecho no es razón suficiente para tener una obligación de obedecerlo. La idea de conformidad respecto a un estándar determinado y establecido es de importancia capital, la cuestión que surge ahora es si esos estándares son jurídicos o morales.

Dada esta imagen de la idea de obediencia que surge del ejercicio del poder de revisión, mi conclusión es que tal obligación es moral y no jurídica. Precisamente el punto medular del desacuerdo entre las distintas teorías del Derecho que se ofrecen hoy en día es la cuestión relativa a si la obligación de obedecer el Derecho es moral o jurídica.

La doctrina de la revisión judicial de las leyes sería imposible sin tener en cuenta un largo periodo histórico de legalismo, caracterizado por el respeto hacia la ley y hacia los intérpretes del Derecho ${ }^{56}$. En mi opinión, la historia del legalismo y del respeto a la ley, desde el punto de vista teórico, consiste en una serie de principios morales reconocidos en la Constitución en la forma de autorizaciones.

Se puede afirmar que, en la medida en que las leyes hayan sido creadas contraviniendo el contenido de aquella autorización y los fines para los cuales han sido dictadas, el grupo sujeto a aquel acuerdo moralmente comprometido no está moralmente obligado a obedecer tales leyes. Y cuando las leyes se dictan en conformidad con el acuerdo moralmente comprometido entonces tal grupo lo asume y le debe moralmente obediencia en conformidad con lo que ha sido ordenado o prohibido. En ambos casos, lo que se presenta como rasgo sobresaliente es la dimensión moral de la obligación y, a partir de esto, la ausencia de una mera imposición en relación con el individuo.

Si partimos de la idea de autorización, es claro que no se sostiene la idea de obligación jurídica. La vinculatoriedad del Derecho se interpreta como generadora de obligaciones no morales sino jurídicas. Que la obligación sea jurídica significa que lo que es mandado o prohibido es obligatorio independientemente del contenido de la ley. Sin embargo, esto no puede ser así si se acepta que la autorización que confiere autoridad a los creadores del Derecho es moral. Como dije, una autorización se otorga a través de lo que se ha denominado acuerdo moralmente comprometido. No es una razón suficiente el que una conducta sea ordenada o prohibida por el Derecho para que reciba obediencia o se considere obligatoria.

El olvido o usurpación por los creadores del Derecho de la dimensión moral de esa autorización es lo que conduce frecuentemente a que un individuo recurra a un Tribunal para enmendar, por decirlo de algún modo, un

${ }^{56}$ Ver cap. 2. nota 11. 
error moral. Si el error se haya en la legislatura debe ser corregido mediante el documento que expresa la autorización, y si está en la Constitución entonces debe ser corregido por el pueblo. El pueblo mismo tiene el poder efectivo para resistir la usurpación sin que sea necesario recurrir a las armas; un rebelde, en este sentido, puede ser alguien que busca la absolución por parte de un juez ${ }^{57}$. El juez, en el ejercicio del poder de revisión, determinará una de las tres siguientes posibilidades: en primer lugar, si un individuo ha recibido o no un trato acorde con lo establecido por la ley; en segundo lugar, si una ley es constitucional ofreciendo razones acerca de su conformidad y mostrando en qué sentido es consistente con la Constitución y, por tanto, estableciendo que no puede ser ya atacada en el futuro; por último, declarar la inconstitucionalidad de la ley calificándola como injusta y contraria a los derechos fundamentales y al ejercicio de la delegación legislativa (ultra vires).

Cuando un juez a través del poder de revisión opta por alguna de estas posibilidades no solo provee las razones constitucionales para el fracaso legislativo en la persecución de la justicia, sino además, el criterio moral de validez y autenticidad de las leyes. Sobre todo, hace patente la limitación moral impuesta a los legisladores en virtud de la autorización o confianza moral que se les ha entregado al momento de su elección para ocupar alguna de las diversas instituciones políticas a las que se les otorga el poder para crear leyes. La posibilidad que se nos presenta es, en esencia, que no es una razón suficiente el que una conducta sea ordenada o prohibida por el Derecho para que reciba obediencia o se considere obligatoria. Ciertamente, se puede afirmar en virtud del propósito de la revisión judicial, que no hay obligación prima facie de obedecer una ley perniciosa o injusta cuando existen limitaciones a la autorización para crear leyes. Es esta limitación moral, impuesta a la autorización para crear leyes a través del poder de revisión, lo que permite acentuar y hacer públicas las razones provistas por el legislativo en la persecución de la justicia. Se puede afirmar contundentemente que la obligación de obedecer el Derecho es moral a la luz del significado de la doctrina de la revisión judicial.

Al margen de lo anterior, otra manera útil para examinar la dimensión moral de la obligación de obedecer el Derecho a través de la doctrina de la revisión judicial consiste en analizar el trasfondo teórico o el contexto histórico de un sistema político democrático en específico en donde la doctrina de la revisión judicial haya sido aceptada y defendida como un elemento del proceso de gobernabilidad y libertad democrática. La tradición norteame-

\footnotetext{
${ }^{57}$ Elliot Jonathan, Debates on the Several State Conventions on the Adoption of the Federal Constitution, $2^{\text {a }}$ ed., 5 v.v. (J.B. Lippincott, 1881), pp. 94, 433.
} 
ricana provee una fuente abundante para un significativo análisis teórico acerca de las bases morales del control judicial de las leyes. Estas bases morales apoyan el argumento a favor de la idea de que el respeto al Derecho, unido al ideal americano de la libertad democrática, es moral y no jurídico. Tomando en cuenta el trasfondo teórico de la Constitución norteamericana, la exigencia de conformidad de las leyes impuesta a través de la figura de la revisión judicial está relacionada con los principios morales que apoyan las provisiones constitucionales. En este sentido, la esencia de la legitimidad constitucional de la revisión judicial está fundada sobre los principios morales articulados en el documento constitucional, y en consecuencia, la idea de conformidad que implica invalidar las leyes por razón de su inconstitucionalidad hace referencia también a criterios morales. Esto sustenta la idea de que la obligación de obediencia al Derecho, vista desde la perspectiva constitucional inherente a la esencia de la revisión judicial, es externa al Derecho, i.e., tiene relación con el contenido. Esto significa por tanto que la obligación de obedecer el Derecho es derivativa. ¿Cuáles son entonces las bases morales o criterios morales involucrados en este trasfondo teórico?

El trasfondo teórico, origen y fuentes de la Constitución norteamericana, se rastrean con anterioridad a su ratificación en el año 1787. "Sus fuentes" afirma Gordon Wood, "hacen referencia, al parecer, a la totalidad de su historia pasada. Ningún pensador o idea han sido tan remotos o tan obscuros como para estar implicados de un modo u otro en la creación de la Constitución"58. Los fundadores del Estado norteamericano estaban profundamente interesados en cuestiones de filosofía política y ese conjunto de ideas y principios conformaron la prevaleciente cultura política que domina el contenido y naturaleza de las disposiciones expresadas en la constitución. La cuestión que surge ahora es ¿cuáles son las características de esa cultura política y en qué sentido constituyen la idea de una base moral como elemento significativo no sólo de una comprensión cabal de esa Constitución, sino también de una adecuada descripción de la base moral de la obligación surgida de la misma? En opinión de Gordon Woods

"La característica más sobresaliente de esa cultura política fue el republicanismo, un conjunto de ideas y valores tan profundamente arraigados que conforman los antecedentes del pensamiento americano. Este cuerpo de ideas no sólo determinó el sistema político de elección en el que creían los Fundadores, también determina sus fines morales y sociales ${ }^{59}$.

${ }^{58}$ Gordon S. Word, “The Intellectual Origin of the American Constitution”, The National Forum. The Phi Kappa Phi Journal, vol. Ixiv, No. 4, (1984), p. 5.

${ }^{59}$ Ibíd., p. 5. 
El conjunto de valores cívicos y morales que conforman la base de los fines sociales y morales que esta cultura republicana se esfuerza por alcanzar tiene sus orígenes en la era de esplendor de la República Romana. Este periodo de la Ilustración romana, en donde pueden encontrarse escritores como Cicerón, Salustio, Tacio, Plutarco etc., legó “una colección de escritos que incorporan creencias y valores acerca del bienestar, la ciudadanía, la salud política y la moralidad social que han perdurado en la cultura occidental"60. Uno de esos efectos puede observarse en el período del Renacimiento, una fase que recalca la tradición de una concepción clásica de la moral política, esto es, una moralidad que reafirma el carácter virtuoso de los ciudadanos independientes como un prerrequisito para el buen gobierno ${ }^{61}$.

Esta concepción clásica de la moralidad política influyó en la cultura del Norte de Europa ${ }^{62}$. Las pruebas de esto pueden hallarse en los escritos de filósofos ingleses y teóricos políticos como John Locke, John Trenchard, Thomas Gordon y en el Contrato Social de Jean Jacques Rousseau. El contenido predominante de estos escritos no sólo consiste en la idea del republicanismo; una gran parte de sus escritos está dedicada además a la teoría del gobierno equilibrado y a la doctrina de la separación de poderes ${ }^{63}$. Estos fueron escritos iniciales que se nutrieron de la doctrina del Derecho natural vigente en aquellos momentos de crisis política, de altibajos e inestabilidad. Las ideas de libertad personal y política, de las limitaciones constitucionales e institucionales en el uso de los poderes gubernamentales, del rule of law y no del rule by law, de la propiedad privada ${ }^{64}$, y la idea de los derechos fundamentales o derechos naturales de todos los hombres -propia de la doctrina del Derecho natural de la época-, fueron los ideales de importancia moral y social que conformaron el antecedente teórico de la Constitución americana. Es durante este período en el que algunos estudiosos rastrean los “fundamentos de Derecho natural” de la Constitución americana ${ }^{65}$. Partiendo de ese antecedente, puede decirse que las bases para el apoyo o rechazo del pueblo hacia las leyes derivan de la presencia o ausencia de los valores morales inherentes a tales leyes. La filosofía constitucional de la época se centró en la idea de justicia y libertad para todos, principios que fueron recogidos de la tradición del Derecho natural. La realidad constitucional de la cual la doctrina de la revisión judicial es parte significa que las leyes deben

\footnotetext{
${ }^{60}$ Ibíd., p. 6.

${ }^{61}$ Ibíd., p. 6

${ }^{62}$ Ibíd., p.6

${ }^{63}$ Ibíd., p. 7.

${ }^{64}$ Ibíd., p. 8.

${ }^{65}$ Lon Fuller, op. cit., p. 99.
} 
dictarse en conformidad con esos estándares y garantías que constituyen la base de esa filosofía constitucional.

A la luz de estas ideas, resulta que la obligación de obedecer el Derecho que surge de la doctrina de la revisión judicial es moral, o de manera exacta, que deriva del contenido del Derecho y, por tanto, es externa al mismo. A partir del conjunto de ideas que surgen en torno a la esencia de la práctica de la revisión judicial es claro que un individuo se encuentra bajo la obligación de obedecer el Derecho una vez que puede afirmarse que dicha ley ha sido dictada en conformidad con los estándares constitucionales, cuyo marco filosófico consiste en la idea de justicia, equidad y libertad para todos, principios que hayan su expresión en la doctrina del Derecho natural.

Una vez que se mostró la conexión entre la revisión judicial y la obligación de obedecer el Derecho ¿se sigue que una ley inválida no es Derecho? Esta objeción puede reformularse de la siguiente manera. En primer lugar, puede significar que una ley inválida no era una ley. Así mismo, es posible que la idea exprese que actos o leyes del legislativo sólo poseen, presumiblemente, una "sombra de Derecho" y no la "sustancia o figura del Derecho", a menos que hayan pasado por un examen popular o institucional, siendo la revisión judicial uno de estos criterios. Puede significar también que lo que la revisión judicial en verdad permite es cuestionar el procedimiento y no la sustancia de la promulgación, de tal manera que lo que es declarado inválido no es la ley sino el criterio formal procedimental a través del cual se crea. El razonamiento detrás de estas posturas es la idea según la cual "aquello que la ley ordena no puede ser ilegal porque lo que ésta dice y provee es en sí el Derecho y la forma más respetable de Derecho [...] es el Derecho lo que prevalece sobre cualquier forma de Derecho y la Corte no es nadie para sostener que una promulgación del parlamento, la ley más respetable, es ilegal”66.

Éstas son objeciones comprensibles respecto al significado de la revisión judicial y la obligación de obedecer el Derecho. Sin embargo, mi discrepancia radica en el hecho de que estos argumentos interpretan las cosas de un modo incorrecto. En primer lugar, puede no ser cierto que lo que fue declarado inválido no constituía Derecho. Si no lo fuera, entonces surge la pregunta acerca de cómo fue presentada ante la Corte como ley, o cómo fue que se interpretó como generadora de obligaciones. Cuando los jueces la declaran como inválida es evidente que ya era cumplida o que existía un rechazo en cuanto a su cumplimiento debido a que ya era ley, y es esto lo que nos confirma la razón por la cual fue llevada a juicio. Frecuentemente, el argumento es que lo que es Derecho y lo que se ha sujetado a un criterio

${ }^{66}$ J. Ungoed-Thomas, en Cheney v. Conn, (1968) ALL. ER. 779, 782. 
procedimental, no puede ser declarado como no Derecho. Pero esto dista de ser cierto, hay ciertas leyes que han sido sujetas a un procedimiento formal y aún así, dejan de ser leyes si son invalidadas por un alto tribunal por determinadas razones. Por ejemplo, en un Estado federal, cuando el gobierno central y un Estado federado crean simultáneamente una ley ejercitando sus propias competencias aunque con contenidos en conflicto. En este caso, la ley sancionada por la primera autoridad prevalece sobre la creada por la segunda, y la ley sancionada por la última deja de ser ley. En tales casos, una ley válida deja paso a la otra. Una deja de ser ley con el tono que lo determina siempre expresado como "en la medida de la inconsistencia declarada nula”. El hecho de que los jueces interpreten las leyes, las revisen y perfilen sus contenidos, no significa que no fueran "leyes" antes de su interpretación y revisión. La arcilla es arcilla antes, durante y después de que ha sido moldeada ${ }^{67}$. Es posible que los jueces declaren un acto nulo $a b$ initio, lo que significa que no había Derecho desde un principio, aunque también es posible declararlos inválidos o como no Derecho en aquel momento de la revisión. A la luz de lo anterior por tanto, sigue siendo inteligible y nada ha sido interpretado erróneamente cuando se dice que la revisión judicial sí declara una ley como inválida y, que en este sentido, deja de ser vinculante para los individuos o deja de generar obligaciones.

De lo anterior surge la segunda objeción aparente, i.e., que las leyes sólo son la "sombra" y no la sustancia del Derecho. Si sólo son sombra, no hubieran sido presentadas como Derecho, pero el hecho es que han sido presentadas y obedecidas como leyes que regulan la vida de las personas. Sin embargo, la tercera objeción aparenta mayor solidez, es decir, que no se trata de declarar una ley como inválida sino únicamente el criterio procedimental. En otras palabras, "que la revisión judicial tiene que ver no con la decisión sino con el proceso creador de la decisión ${ }^{68}$. A esto puede replicarse que si la revisión judicial es aplicable al proceso creador de leyes también es aplicable por extensión a la decisión misma, ya que los fallos en el proceso de creación se reflejan también en la decisión o sustancia de la ley promulgada. Como tal, la revisión judicial no tiene que ver solamente con el proceso creador sino también con el contenido del Derecho. La promulgación de una ley mala o injusta puede declararse inválida y por tanto como no Derecho una vez que dicha promulgación es contraria a las limitaciones constitucionales. La cuestión pertinente no es por qué tal ley debió haber sido aceptada, sino que la revisión judicial, a partir de su justificación constitucional, puede

${ }^{67}$ Dias, op. cit., p. 452.

${ }^{68}$ Lord Brightman, en Chief Constable of North Wales Police v. Evans, (1982) 3 ALL ER 141, 154, (1982) 1 WLR 115, 1173. 
declarar tales leyes inválidas, es decir, como no Derecho en la medida de su inconsistencia e inconformidad.

Examinada en su conjunto, la esencia de la doctrina de la revisión judicial tiene su origen en un fundamento de Derecho natural inherente a la Constitución americana. Esto se puede afirmar a partir de sus antecedentes teóricos y de las ideas filosóficas y políticas, esto es, de los fines morales y sociales y los valores de gobierno limitado y gobierno equilibrado etc., sobre los que está fundada. De esto se sigue que la revisión judicial, a la luz de las provisiones constitucionales así como de las ideas de la doctrina del Derecho natural, determina el criterio por el cual identificamos, explicamos y evaluamos el Derecho positivo ${ }^{69}$ que opera dentro del marco del espíritu democrático. Por tanto, una reconstrucción adecuada de la obediencia al Derecho positivo dentro del marco democrático deberá hallarse recurriendo al criterio o base por el cual dichas leyes son identificadas, explicadas y evaluadas en su conjunto. Una vez que se entiende que ésta es la imagen correcta de la revisión judicial y de su esencia, se pone claramente de manifiesto que la revisión judicial, como medio que provee de dicho criterio evaluativo, no solamente implica que la obediencia al Derecho es de naturaleza moral y no jurídica, sino que además, es de suma importancia para mostrarnos el problema teórico de la obediencia al Derecho.

(Trad. de Leopoldo Gama)

${ }^{69}$ Véase Olufemi Taiwo, op. cit., p. 39. 